\title{
Prevalence, severity, and risk indicators of gingival inflammation in a multi-center study on South American adults: a cross sectional study
}

Paola CARVAJAL ${ }^{1}$, Mariel GÓMEZ², Sabrina GOMES ${ }^{3}$, Ricardo COSTA ${ }^{3}$, Andres TOLEDO², Fernando SOLANES', Hugo ROMANELLI'², Rui OPPERMANN ${ }^{3}$, Cassiano RÖSING ${ }^{3}$, Jorge GAMONAL ${ }^{1}$

\footnotetext{
1- Universidade de Chile, Facultad de Odontología, Departamento de Odontología Conservadora, Laboratorio de Biología Periodontal, Santiago, Chile. 2- Universidad Maimónides, Facultad de Odontología, Buenos Aires, Argentina.

3- Universidade Federal do Rio Grande do Sul, Faculdade de Odontologia, Departamento de Odontologia Conservadora, Porto Alegre, Brasil.
}

Corresponding address: Jorge Gamonal. Laboratorio de Biología Periodontal - Departamento de Odontología Conservadora - Facultad de Odontología - Universidad de Chile - Sergio Livingstone Pohlhammer 943 - 83800 - Independencia - Santiago - Chile - Phone: +56 229781833 - Fax: +56 229781815 e-mail: jgamonal@odontologia.uchile.cl

Submitted: April 2, 2016 - Modification: June 5, 2016 - Accepted: June 27, 2016

\section{ABSTRACT}

$\mathrm{O}$ bjectives: The aim of this study is to investigate the prevalence and severity of gingival inflammation and associated risk indicators in South American adults. Material and Methods: Multi-stage samples totaling 1,650 adults from Porto Alegre (Brazil), Tucumán (Argentina), and Santiago (Chile) were assessed. The sampling procedure consisted of a 4-stage process. Examinations were performed in mobile dental units by calibrated examiners. A multivariable logistic regression model was utilized for associating variables as indicators of gingival inflammation (GI) (Gingival Index $\geq 0.5$ ). Statistical significance was set at 0.05 . Results: A total of $96.5 \%$ of the adults have GI. Regarding the severity of $\mathrm{Gl}, 22.5 \%$ of participants examined have mild GI , $74.0 \%$ have moderate $\mathrm{GI}$, and $3.6 \%$ have severe Gl. The multivariate analyses identify the main risk indicators for $\mathrm{Gl}$ as adults with higher mean of Calculus Index $(\mathrm{OR}=18.59)$; with a Visible Plaque Index $\geq 30 \%$ $(O R=14.56)$; living in Santiago $(O R=7.17)$; having $\leq 12$ years of schooling $(O R=2.18)$, and females $(\mathrm{OR}=1.93)$. Conclusions: This study shows a high prevalence and severity of gingival inflammation, being the first one performed in adult populations in three cities of South America.

Keywords: Gingival diseases. Periodontal index. South America.

\section{NTRODUCTI ON}

Gingival inflammation (GI) is a common clinical feature detected in children and adults ${ }^{1}$. It is characterized by swelling, redness, and bleeding at the gums and it is described as an inflammatory reaction upon the pro-inflammatory cytokines that modulate the balance between humoral and cellassociated immune responses ${ }^{28}$. This clinical feature is characteristic of both gingivitis and periodontitis. $\mathrm{Gl}$ is considered to be one major class of periodontal conditions, and is recognized to result from the increase in supragingival plaque and the ensuing interactions between the microbiota of biofilm and host response ${ }^{26}$. Consequently, the prevention of plaque accumulation and early treatment of $\mathrm{Gl}$ reduce the risks associated with the development of the more destructive periodontal disease ${ }^{5}$, which has also been associated with systemic conditions ${ }^{8}$.

Understanding the epidemiologic pattern of GI is essential for planning appropriate public-health services. It has been clearly demonstrated that plaque-induced $\mathrm{Gl}$ is prevalent at all ages of the dentate population ${ }^{2,29}$. In recent decades, crosssectional and longitudinal epidemiological studies on periodontitis in adults were performed in Chile ${ }^{12}$ and Brazilit ${ }^{4}$. Moreover, analytical approaches designed to identify associated factors that could be risk indicators for gingival inflammation are nonexistent. Our main objective in this multi-center, populationbased, cross-sectional and epidemiological study is to investigate the prevalence, severity, and 
risk indicators for gingival inflammation in representative samples of the adult populations of Porto Alegre (Brazil), Tucumán (Argentina), and Santiago (Chile).

\section{MATERI AL AND METHODS}

\section{Study design, sampling, and sample sizes}

The present cross-sectional, representative study utilized stratified, multistage probability samples of the civilian, noninstitutionalized adult populations in three South American cities. Data were collected between J anuary and J uly of 2014 .

Our sampling approach considered various age subgroups (18-19; 20-29; 30-39; 40-49; and $\geq 50$ years of age). Considering previously published information that estimated a prevalence of gingivitis of $93.9 \%{ }^{21}$ (average Gingival Index $\geq 0.5$ ) with a precision rate of $95 \%$ and a $2 \%$ error, we determined that a sample size of 550 adults would be appropriate for each of the three cities in the study. To do so, the formula to estimate the prevalence of a population $\left(n=Z^{2}{ }_{1-\alpha / 2} P(1-P) / e^{2}\right)$ was used.

The study participants were selected using a multi-staged probability sampling process. Age groups were formed according to a proportional approach to the base population registries in the total of urban administrative regions in Porto Alegre, Tucumán, and Santiago, according to the last census in each city, and considering differences in gender and age.

The sampling process consisted of four stages: City (primary sampling units - $1^{\text {st }}$ stage); Tract census ( $2^{\text {nd }}$ stage); Blocks ( $3^{\text {rd }}$ stage); and Individuals within the age group ( $4^{\text {th }}$ stage). The cities were chosen according to logistics and interests in the three countries. Using maps of each city, primary census sectors were randomly chosen. The number of sectors in each city was determined according to the city size and census distribution. If the access to a primary census sector was not possible, the next available census sector was chosen. In each census sector, the blocks were randomly chosen. On each block, households were consecutively approached according to the sector starting point, until the number of participants expected for each sector was reached. Places such as nursing homes and commercial establishments were not included. When no potential participants were available for examination in a household, the next household was visited.

Candidates who have expressed an interest in participating in the study were selected based on the following criteria: 18 years of age or older, healthy, and with at least four permanent teeth. Were excluded from the study candidates needing antibiotic prophylaxis prior to dental examination, women who were pregnant or breastfeeding, individuals with fixed orthodontic appliances, or individuals who chronically used nifedipine, cyclosporine, phenytoin, or any prescription medicines that might interfere with the study outcome.

The protocol used for this study is in accordance with the Declaration of Helsinki and was reviewed and approved by the Institutional Review Boards of the University of Chile, Federal University of Rio Grande do Sul, and Maimonides University. All study participants were informed about the aims of the study and signed an informed consent form.

\section{Clinical evaluation and sociodemographic and behavioral data}

A sociodemographic and general health interview was conducted and a structured questionnaire, consisting of open and closed questions about demographics, habits, attitudes, and knowledge related to oral health, was designed and administered to all participants. This questionnaire was tested at each of the three study sites and adapted according to the necessities of the local population. Finally, a complete dental examination was performed on all participants in the study.

Prior to the initiation of the study, the principal investigators and examiners met in Porto Alegre in order to standardize diagnostic criteria with the reference examiner (CR). Intra- and inter-examiner kappa coefficients for the Visible Plaque Index, Calculus Index, and Gingival Index were above 0.7. In addition, the structured questionnaire was standardized for each of the three study locations.

Each team consisted of one clinical examiner, totaling three dental examiners (RC, AT, FS) and each conducted exams using a manual periodontal probe (UNC-15) and mobile dental units. Good clinical practice standards were used and warranted. Periodontal clinical parameters were evaluated in all teeth, excluding third molars. The parameters evaluated were Visible Plaque Index (VPI), Calculus Index $(\mathrm{Cl})$, and Gingival Index (G-Index). Visual plaque assessment was determined using absence (0) or presence (1) of dental plaque according to Ainamo \& Bay. The Löe modification of the LöeSilness index was used to evaluate gingival health. Each tooth was divided into six surfaces, three facial and three lingual, as follows: 1) mesio-facial; 2) mid-facial; 3) disto-facial; 4) mesio-lingual; 5) mid-lingual; and 6) disto-lingual. Third molars and those teeth with cervical restorations or prosthetic crowns were excluded from the scoring procedure. Absence (0) or presence (1) of calculus was scored in lower anterior teeth $(\mathrm{Cl})$. Each tooth was divided into three lingual surfaces, as follows: disto-lingual, medio-lingual, and mesio-lingual. At the end of clinical examinations, those participants who were 
diagnosed with periodontal pathologic conditions were provided a written report of their condition and advised to seek an oral health consultation.

\begin{tabular}{|c|c|c|}
\hline & \multicolumn{2}{|c|}{ QUESTIONNAIRE } \\
\hline \multicolumn{3}{|l|}{ DATE: } \\
\hline \multicolumn{3}{|c|}{ GENERAL INFORMATION } \\
\hline \multicolumn{3}{|c|}{ Number Questionnaire } \\
\hline \multicolumn{3}{|c|}{ Birth date } \\
\hline \multicolumn{3}{|l|}{ Age in Years } \\
\hline \multirow[t]{2}{*}{ Gender } & \multicolumn{2}{|c|}{ Female } \\
\hline & \multicolumn{2}{|c|}{ Male } \\
\hline \multicolumn{3}{|c|}{ Place of residence } \\
\hline \multicolumn{3}{|c|}{ SOCIOCULTURAL LEVEL } \\
\hline \multicolumn{3}{|c|}{ 1. Currently you are: } \\
\hline 1 & \multicolumn{2}{|c|}{ Working } \\
\hline 2 & \multicolumn{2}{|c|}{ Unemployed } \\
\hline 3 & \multicolumn{2}{|c|}{ Voluntary work } \\
\hline 4 & \multicolumn{2}{|c|}{ Studying } \\
\hline 5 & Stud & and working \\
\hline 6 & Reti & \\
\hline 2. What kind & ation & you received? \\
\hline 1 & With & ducation \\
\hline 2 & Som & mentary school \\
\hline 3 & Elen & ry school \\
\hline 4 & Som & h school \\
\hline 5 & High & \\
\hline 6 & Prof & nal degree \\
\hline 7 & Som & ege \\
\hline 8 & Coll & egree \\
\hline 9 & Grac & degree \\
\hline GENERAL H & & \\
\hline $\begin{array}{l}\text { 3. Have you } \\
\text { following illne }\end{array}$ & agnos & th any of the \\
\hline 1 & No & \\
\hline 2 & Yes & Which? \\
\hline & 1 & Diabetes \\
\hline & 2 & Arterial hypertension \\
\hline & 3 & Obesity \\
\hline & 4 & Myocardial infarction \\
\hline & 5 & Stroke \\
\hline & 6 & Pneumonia \\
\hline & 7 & Asthma \\
\hline & 8 & Osteoporosis \\
\hline & 9 & Depression \\
\hline & 10 & Cancer \\
\hline & 11 & Other \\
\hline 4. Do you use & edica & ermanently? \\
\hline 1 & No & \\
\hline 2 & Yes & Which? \\
\hline & 1 & Anxiolytic \\
\hline & 2 & Antihypertensive \\
\hline & 3 & Anticoagulant \\
\hline & 4 & For cholesterol \\
\hline & 5 & For thyroid disorders \\
\hline & 6 & For cardiac disorders \\
\hline & 7 & Hormonal support \\
\hline & 8 & Cancer treatment \\
\hline & 9 & Diabetes treatment \\
\hline & 10 & Contraceptives \\
\hline & 11 & Other (specify) \\
\hline SMOKING H & & \\
\hline 5. Have you & oked & \\
\hline 1 & $\mathrm{Nev}$ & oked \\
\hline 2 & Smo & ut quit \\
\hline 3 & Curr & smoking \\
\hline 6. If you smo & man & s have you been smoking? \\
\hline $\begin{array}{l}\text { 7. If you smo } \\
\text { on average? }\end{array}$ & man & rettes do you smoke a day \\
\hline
\end{tabular}

Questionnaire- Structured questionnaire, consisting of open and closed questions about demographics, habits, attitudes, and knowledge related to oral health

\section{Definition of variables}

The prevalence of gingival inflammation was defined as the percentage of study participants with a mean Gingival Index (G-Index) $\geq 0.5$. Gingival Bleeding Index (GBI) was defined as the percentage of sites with G-Index $\geq 2$. When appropriate, estimates were isolated for interproximal sites. Severity of gingival inflammation was defined as G-Index 0.5-1.0 for mild, 1.1-2.0 for moderate, and $>2.0$ for severe gingival inflammation. Study participants were classified by their smoking habits as either nonsmokers or smokers. Smokers were further classified as light (5 cigarettes per day), moderate (5-10 per day), and heavy (over 10 per day). The educational level of the study participants was also categorized as $\leq 12$ or $>12$ years of school. The G-Index, VPI, GBI, and $\mathrm{Cl}$ indices are represented in the data as mean values.

\section{Statistical analyses}

Continuous data are presented as means \pm SDs, and categorical variables are presented as percentages. The data are stratified according to sociodemographic, behavioral, and periodontal values. Chi-square tests were applied to compare distributions of periodontal variables between age groups and centers; to assess differences in the means and percentages, Mann-Whitney or KruskallWallis tests were applied, and statistical analyses were performed using a statistical software package (Stata/IC 13.1). A multi-variable logistic regression model was built to assess the contribution of each variable (age, gender, smoking, and social or cultural factors). The occurrence of gingival inflammation was considered if G-Index $\geq 0.5$. In addition, variables were analyzed in the model and allowed if the coefficient was modified by at least $10 \%$. VPI was dichotomized at $30 \%$. Odds ratios were calculated with $95 \%$ confidence intervals, and statistical significance was defined as $p<0.05$.

\section{RESULTS}

A total of 1650 adults from Porto Alegre, Tucumán, and Santiago participated in this study. Females represent $52.5 \%$ of the overall study participants, while one third of the participants are in the $\geq 50$ years age group.

\section{Prevalence of gingival inflammation}

Table 1 shows that the overall prevalence of gingival inflammation (mean G-Index $\geq 0.5$ ) for the study population is $95.6 \%$. The Santiago and Porto Alegre participants present a significantly higher prevalence of gingival inflammation $(p<0.001)$ at $99.1 \%$ and $97.3 \%$, respectively, as compared with participants from Tucumán, at $90.4 \%$. Only in Porto Alegre the prevalence of gingival inflammation in 
the $\geq 50$ years age group is significantly higher than in the 40-49 and 20-29 years age groups $(p<0.05)$. When the total sample is considered, a significant difference is observed between the prevalence of gingival inflammation in the 20-29 (92.3\%) and the $\geq 50$ years age groups $(97.3 \%, \mathrm{p}<0.05)$ for Porto Alegre and Tucumán, but not for Santiago.

Considering the total sample of the present study, no statistically significant difference is observed between genders (Table 2). In the entire

Table 1- Prevalence of gingival inflammation (mean G-Index $\geq 0.5$ ) according to age per city

\begin{tabular}{|c|c|c|c|c|c|c|c|c|c|c|}
\hline \multirow{3}{*}{$\begin{array}{c}\text { Age } \\
\text { (years) }\end{array}$} & \multirow{2}{*}{\multicolumn{2}{|c|}{$\begin{array}{c}\text { PORTO ALEGRE }{ }^{\star \star} \\
\text { Gingival } \\
\text { Inflammation } \\
\end{array}$}} & \multirow{2}{*}{\multicolumn{2}{|c|}{$\begin{array}{c}\text { TUCUMÁN } \\
\text { Gingival } \\
\text { Inflammation }\end{array}$}} & \multirow{2}{*}{\multicolumn{2}{|c|}{$\begin{array}{l}\text { SANTIAGO } \\
\text { Gingival } \\
\text { Inflammation }\end{array}$}} & \multicolumn{4}{|c|}{ TOTAL ** } \\
\hline & & & & & & & $\begin{array}{r}\text { Gi } \\
\text { Infla। }\end{array}$ & $\begin{array}{l}\text { al } \\
\text { ation }\end{array}$ & & \\
\hline & $n$ & $(\%)$ & $n$ & $(\%)$ & $n$ & $(\%)$ & $\mathrm{n}$ & (\%) & $\mathrm{n}$ & (\%) \\
\hline $18-19$ & 24 & 100 & 29 & 93.5 & 24 & 100 & 77 & 97.5 & 79 & 4.8 \\
\hline $20-29$ & 98 & 94.2 & 125 & 85.0 & 126 & 99.2 & 349 & 92.3 & 378 & 22.9 \\
\hline $30-39$ & 115 & 96.6 & 115 & 91.3 & 101 & 98.1 & 331 & 95.1 & 348 & 21.1 \\
\hline $40-49$ & 102 & 95.3 & 86 & 94.5 & 102 & 100 & 290 & 96.7 & 300 & 18.2 \\
\hline$\geq 50$ & 196 & 100 & 142 & 91.6 & 192 & 99.0 & 530 & 97.3 & 545 & 33.0 \\
\hline Total & 535 & $97.3^{*}$ & 497 & $90.4^{*}$ & 545 & $99.1^{*}$ & 1577 & 95.6 & 1650 & 100 \\
\hline
\end{tabular}

$\left({ }^{*}\right)$ p-value $<0.001$, Fisher's exact test to assess differences between prevalence of gingival inflammation Tucumán versus P. Alegre and Santiago

$\left.{ }^{(* *}\right)$ p-value $<0.05$, Fisher's exact test to assess differences between prevalence of gingival inflammation and age

Table 2- Prevalence of gingival inflammation according to risk indicators per city

\begin{tabular}{|c|c|c|c|c|c|c|c|c|c|c|c|c|}
\hline \multirow[t]{3}{*}{ Variables } & & \multicolumn{11}{|c|}{$\begin{array}{c}\text { PREVALENCE OF GINGIVAL INFLAMMATION } \\
\text { BY CITY AND TOTAL }\end{array}$} \\
\hline & & \multirow[t]{2}{*}{$\mathbf{n}$} & \multirow[t]{2}{*}{$(\%)$} & \multicolumn{2}{|c|}{$\begin{array}{l}\text { PORTO } \\
\text { ALEGRE }\end{array}$} & \multicolumn{2}{|c|}{ TUCUMÁN } & \multicolumn{2}{|c|}{ SANTIAGO } & \multicolumn{2}{|c|}{ TOTAL } & \multirow[t]{2}{*}{ p-value ${ }^{\star \star}$} \\
\hline & & & & $\mathbf{n}$ & $(\%)$ & $\mathbf{n}$ & $(\%)$ & $\mathbf{n}$ & $(\%)$ & $\mathbf{n}$ & (\%) & \\
\hline \multirow[t]{2}{*}{ Gender } & Female & 867 & 52.6 & 275 & 98 & 274 & 92.6 & 286 & 98.3 & 835 & 96.3 & \\
\hline & Male & 783 & 47.5 & 260 & 96.3 & 223 & 87.8 & 259 & 100 & 742 & 94.8 & 0.127 \\
\hline \multirow{2}{*}{$\begin{array}{l}\text { Education } \\
\text { (years) }\end{array}$} & $\leq 12$ & 1099 & 66.6 & 424 & 97.9 & 352 & $94.9^{*}$ & 293 & 99.3 & 1069 & $97.3^{*}$ & \\
\hline & $>12$ & 551 & 33.4 & 111 & 94.9 & 145 & 81.0 & 252 & 98.8 & 508 & 92.2 & 0.000 \\
\hline \multirow[t]{4}{*}{ Smoking } & No & 1180 & 71.5 & 384 & 96.7 & 368 & 89.5 & 368 & 98.9 & 1120 & 94.2 & \\
\hline & Current (light) & 171 & 10.4 & 17 & 100.0 & 57 & 96.6 & 94 & 98.9 & 168 & 98.3 & \\
\hline & Current (moderate) & 76 & 4.6 & 24 & 96.0 & 17 & 94.4 & 33 & 100.0 & 74 & 97.4 & \\
\hline & Current (heavy) & 223 & 13.5 & 110 & 99.1 & 55 & 88.7 & 50 & 100.0 & 215 & 96.4 & 0.194 \\
\hline \multirow[t]{2}{*}{$\begin{array}{l}\text { Self-reported } \\
\text { diabetes }\end{array}$} & $\begin{array}{c}\text { No } \\
\text { diabetes }\end{array}$ & 1528 & 92.6 & 489 & 97.0 & 493 & 90.3 & 473 & 99.0 & 1455 & 95.2 & \\
\hline & Yes & 122 & 7.4 & 46 & 100 & 4 & 100 & 72 & 100 & 122 & $100^{*}$ & 0.005 \\
\hline \multirow{2}{*}{$\begin{array}{l}\text { Self-reported } \\
\text { hypertension }\end{array}$} & No hypertension & 1332 & 80.7 & 379 & 96.4 & 443 & 89.5 & 441 & 99.3 & 1263 & 94.8 & \\
\hline & Yes & 318 & 19.3 & 156 & 99.4 & 54 & $98.2^{*}$ & 104 & 98.1 & 314 & $98.7^{*}$ & 0.001 \\
\hline \multirow[t]{2}{*}{ Plaque Index } & $<30 \%$ & 58 & 3.5 & 11 & 64.7 & 7 & 21.2 & 6 & 75.0 & 24 & 41.4 & \\
\hline & $\geq 30 \%$ & 1592 & 96.5 & 524 & $98.3^{*}$ & 490 & $94.8^{*}$ & 539 & $99.5^{\star}$ & 1553 & $97.6^{*}$ & 0.000 \\
\hline
\end{tabular}

(*) p-value $<0.05$, Fisher's exact test, to assess differences between prevalence of gingival inflammation for each variable and city

$\left.{ }^{* *}\right)$ p-value, Fisher's exact test, to assess differences between prevalence of gingival inflammation in the total sample for each variable 
sample, individuals with $\leq 12$ years of education present a gingival inflammation prevalence that is higher than those with $>12$ years of education (prevalence of $97.3 \%$ versus $92.2 \%$, respectively, $\mathrm{p}<0.0001$ ), but this difference is most pronounced

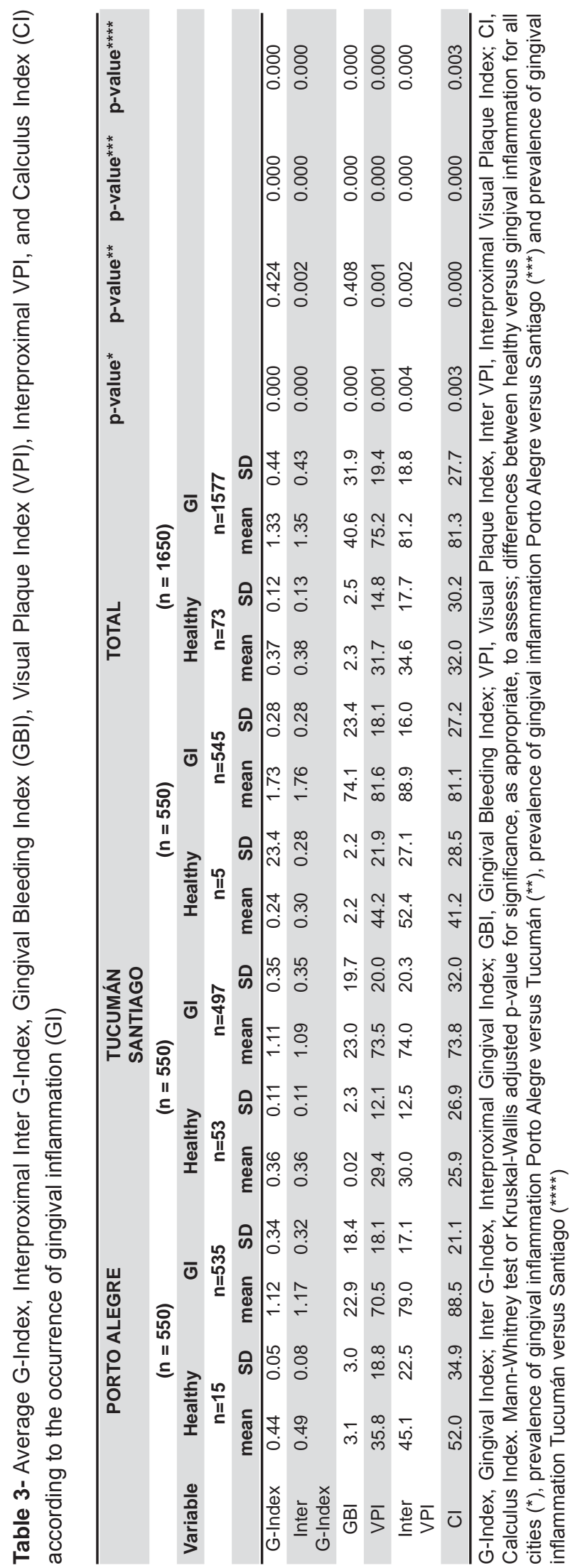

and significant only for the sample of Tucumán $(94.9 \%$ versus $81.0 \%, p<0.05)$ when the three city samples are separately analyzed.

Participants who smoke present a higher prevalence of gingival inflammation as compared with nonsmokers, but the difference was not statistically significant $(p=0.194)$. Those participants with self-reported diabetes and hypertension also present a significantly higher prevalence of gingival inflammation as compared with those not reporting these conditions. Within cities, only in Tucumán there is a statistically significant difference in gingival inflammation prevalence between those who self-report hypertension and those who do not $(98.2 \%$ versus $89.5 \%$, respectively, $p<0.05)$. Adults with a visible plaque index $\geq 30 \%$ present a significantly higher prevalence of gingival inflammation than those with visible plaque index $<30 \%(97.6 \%$ versus $41.4 \%$, respectively, $\mathrm{p}<0.0001$ ) (Table 2).

Table 3 describes all clinical variables examined in this study (mean G-Index, mean GBI, mean VPI, and mean $\mathrm{Cl}$ ). Regarding all of these variables, higher values are observed in individuals with higher gingival inflammation prevalence, compared with lower values in healthy adults $(p<0.001)$ in the three cities. In participants with gingival inflammation, the mean G-Index in interproximal sites is $1.35( \pm 0.43)$ and in all sites is 1.33 $( \pm 0.43)$, without statistically significant differences. Study participants from Santiago had the highest average gingival index (1.73) compared with those from Tucumán and Porto Alegre, at 1.11 and 1.12 , respectively $(p<0.001)$. The mean VPI in interproximal sites is higher than the mean plaque index for all sites examined ( $81 \%$ versus $75 \%$, respectively) for the total study population. Significant differences for the city of Porto Alegre and Santiago are found between interproximal VPI and total VPI. The rates of interproximal VPI in individuals with gingival inflammation in Santiago, Porto Alegre, and Tucumán are $89 \%, 80 \%$, and $74 \%$, respectively, while the mean interproximal VPI values in healthy adults are $45 \%, 30 \%$, and $52 \%$, for Santiago, Tucumán, and Porto Alegre, respectively, with significant differences between them $(p<0.001)$ (Table 3$)$. The mean $\mathrm{Cl}$ rates in individuals with gingival inflammation are $89 \%$ in Porto Alegre, $74 \%$ in Tucumán, and $81 \%$ in Santiago with significant differences between them, while the $\mathrm{Cl}$ rates in healthy adults are $52 \%, 26 \%$, and $41 \%$, respectively (Table 3 ). GBI is higher in individuals classified as having gingival inflammation $(41 \%)$ as compared with healthy adults $(2 \%, p=0.001)$, and $\mathrm{GBI}$ is higher in Santiago as compared with Porto Alegre and Tucumán (Table 3).

Severity of gingival inflammation

Tables $4 \mathrm{a}$ and $4 \mathrm{~b}$ present mean G-Index as 


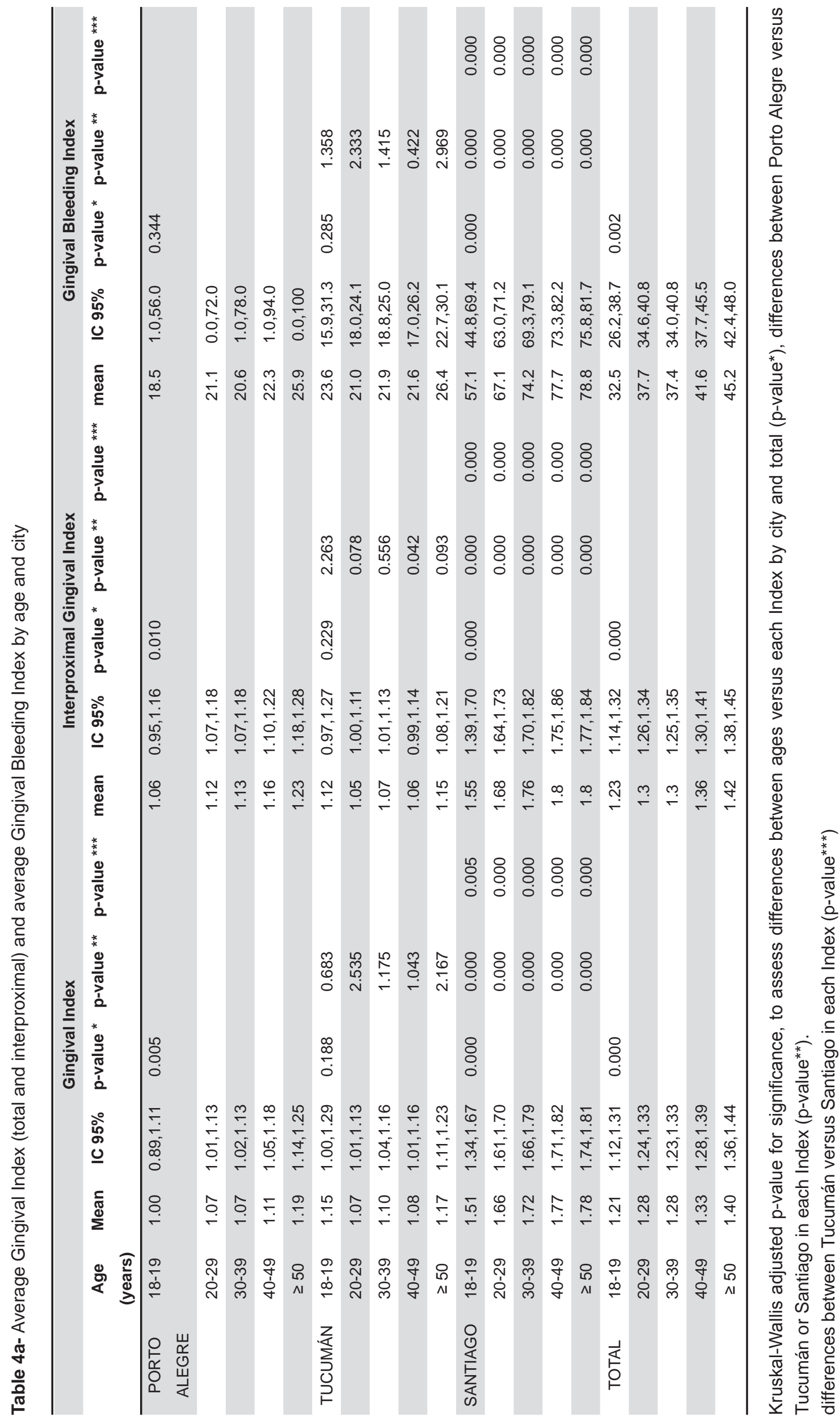




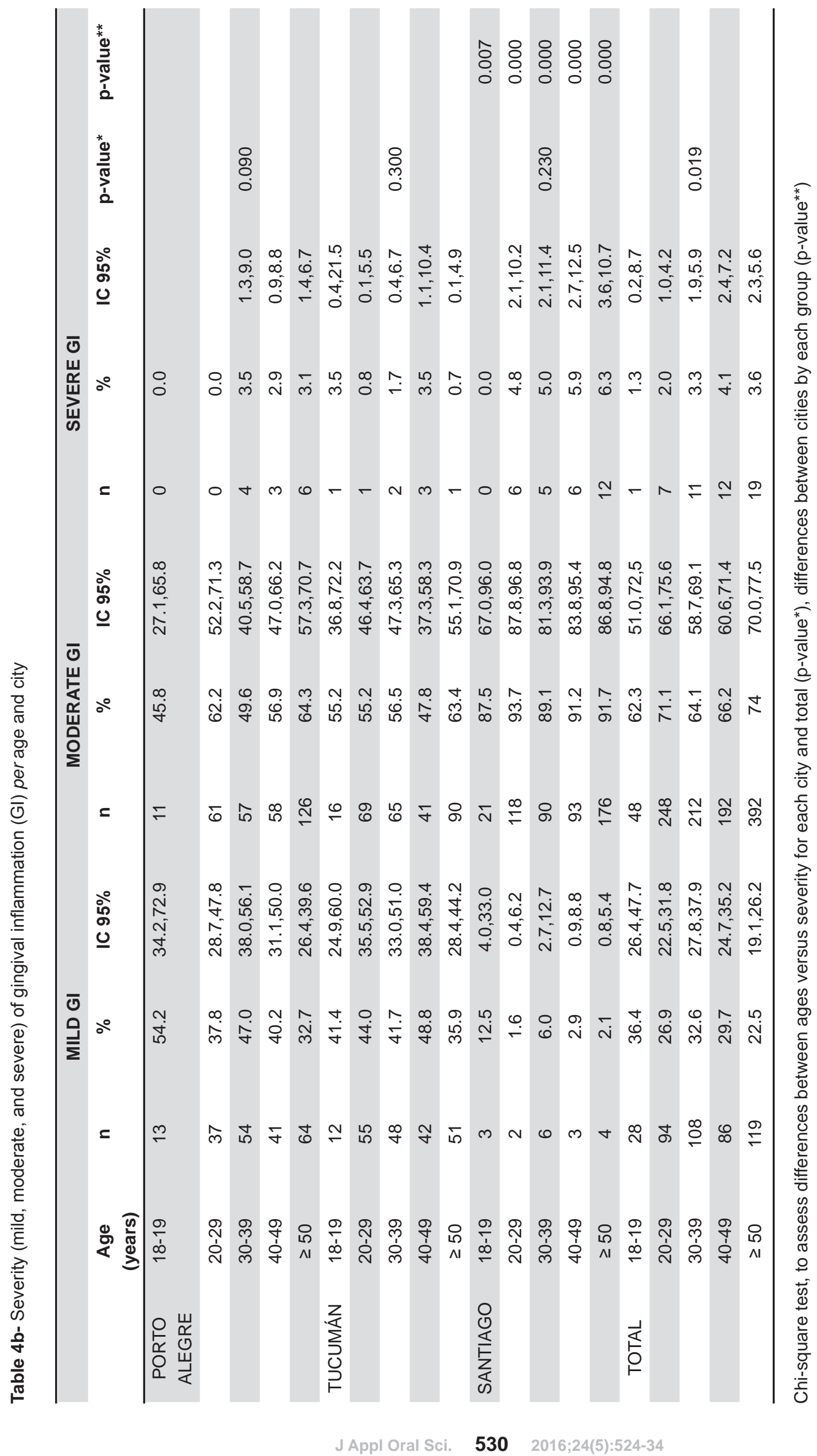


restricted to interproximal surfaces as well as mean $\mathrm{GBI}$ according to age and city. GBI means of $32.5 \%$, $37.7 \%, 37.4 \%, 41.6 \%$, and $45.2 \%$ are found for 18-19 year olds, 20-29 year olds, 30-39 year olds, 40-49 year olds, and $\geq 50$ year olds, respectively (Table 4a). Participants from Santiago showed the highest mean GBI (Table 4a). Regarding the severity of gingival inflammation, $22.5 \%$ of participants examined have mild gingival inflammation, $74.0 \%$ have moderate gingival inflammation, and $3.6 \%$ have severe gingival inflammation. In Santiago, the vast majority of adults present moderate gingival inflammation (90.6\%) and, for all age groups, the gingival inflammation prevalence is higher than what is observed in Porto Alegre and Tucumán (Table 4b).

\section{Risk indicators of gingival inflammation}

The multivariate logistic regression model, which was designed to assess indicators that could be related to gingival inflammation prevalence (G-Index $\geq 0.5$ ) in the adult samples, demonstrates that subjects with higher $\mathrm{Cl}$ mean $(\mathrm{OR}=18.59)$; with a VPI $\geq 30 \%(O R=14.56)$; living in Santiago $(O R=7.17)$; having $\leq 12$ years of schooling $(O R=2.18)$, and females $(O R=1.93)$ are more likely to present gingival inflammation. This model was adjusted for age, presence of diabetes, and selfreported hypertension and smoking (Table 5).

\section{DISCUSSION}

The population examined in the present study is comprised of a random sample of individuals aging 18 years or older from Porto Alegre (Brazil), Tucumán (Argentina), and Santiago (Chile). To our knowledge, this is the first study conducted to assess the prevalence of gingival inflammation in a representative sample of adult populations from three Latin American cities. The sampling strategy that we employed was successful in achieving a representative and balanced sample of participants, since the individuals examined in each age group for each of the three cities are in the same proportion as in the whole study population for the three cities combined. In this study, $95.6 \%$ of the 1650 adults examined from three South American cities present a G-Index $\geq 0.5$. This information corroborates the data reported for adults from J ordan, China, and the United States of America, which demonstrated that adults with a G-Index $\geq 0.5$ comprise $75.8 \%, 97.9 \%$, and $93.9 \%$ of their respective populations ${ }^{1,21,30}$. Comparing our results with that from previous studies is somewhat hindered by the use of different nomenclature and diagnostic criteria across studies. The Community Periodontal Index (CPI) was used to report the occurrence of probing pocket depth, calculus, and gingival inflammation in the
Hungarian adult population, and gingival bleeding $(\mathrm{CPI}=1)$ was observed in $8 \%$ of the population ${ }^{15}$. The National Health and Nutrition Examination Survey III (NHANES III) conducted in the USA between 1988-1994 demonstrated that $50 \%$ of the adult USA population had gingival inflammation, using gingival bleeding as the criterion ${ }^{3}$. A study conducted in I taly, using bleeding on probing (BoP) as the criterion, determined that the prevalence of individuals showing at least one site positive for BoP was $99 \%^{11}$. All the aforementioned studies demonstrate that the occurrence of gingival inflammation is almost universally correlated with poor gingival conditions. In addition, there is a large discussion in the literature regarding how to define disease criteria. It would be interesting to develop guidelines to suggest which criteria should be standardized for use in epidemiological studies for gingival conditions ${ }^{16}$. Concerning the severity of gingival inflammation, the present study shows that $22.5 \%$ of adults have mild gingival inflammation, $74.0 \%$ have moderate gingival inflammation, and $3.6 \%$ have severe gingival inflammation. In contrast, representative studies conducted in Europe and Australia demonstrated that the prevalence of severe gingival inflammation is comparably much higher (17\% and $19.7 \%$, respectively) in these populations ${ }^{15,17}$. The multivariate logistic regression models that we employed show that a female with $\leq 12$ years of schooling, a higher dental calculus index, $\geq 30 \%$ of VPI, and living in Santiago has an increased likelihood of presenting gingival inflammation, when adjusting for age, presence of diabetes, and self-reported hypertension and smoking. In this study, to live in Santiago was a risk indicator for presenting GI. It could be because these subjects had lower oral hygiene habits compared with those from the other cities. Indeed, subjects with presence of GI belonging to Santiago had a higher average percentage of VPI, compared with subjects with GI of Tucumán and Porto Alegre. In fact, the plaque index has been associated with increased presence of gingival inflammation and worst level of oral hygiene in other populations ${ }^{9}$. There are limited studies at the Latin American level on the prevalence of periodontal conditions ${ }^{27}$, which allow contrast with the findings in this study. Although subjects belonging to Santiago present greater gingival inflammation and increased risk of it, is based with those reported for that country, where Chilean adults had a high prevalence of periodontal destruction and indicators of gingival inflammation ${ }^{12}$.

The present study also demonstrates a socioeconomic gradient in the oral health of the populations examined. Participants from lower socioeconomic groups present significantly poorer gingival health as compared with participants in 


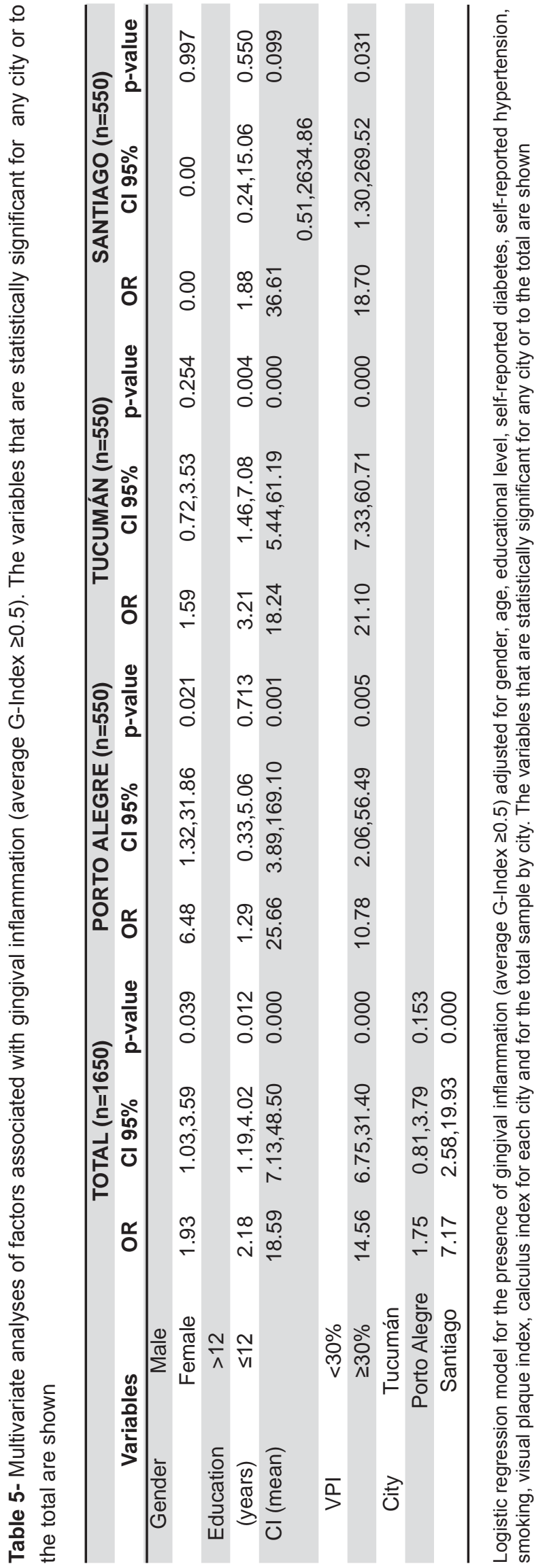

higher socioeconomic groups ${ }^{4}$. In this regard, different explanations have been raised in the literature to explain such findings. For example, those in lower socioeconomic situations are also more likely to smoke, and smoking has been found as a significant risk factor for periodontitis ${ }^{10}$. On the other hand, individuals with higher socioeconomic status are likely to have more positive attitudes regarding oral hygiene and self-care, and better access to available health care options. Therefore, low incomes and low levels of education seem to be variables with good predictability for periodontal diseases ${ }^{7}$. The prevalence of gingival inflammation in females found in the present study contradicts results from Greece, where women have been shown to have better oral hygiene and gingival status than men ${ }^{22}$. Perhaps this difference is more about culture than gender. It should be noted that only when adjusting the multivariate model by confounding variables, female gender appears as a possible risk indicator for the presence of gingival inflammation. On the other hand, the longitudinal recovery of bleeding sites was positively influenced in females ${ }^{25}$.

Regarding the self-reported diabetes and hypertension among our participants, $7.4 \%$ have diabetes and $19.3 \%$ have hypertension. Participants with self-reported diabetes and hypertension present a significantly higher prevalence of gingival inflammation than those not reporting these conditions. Previous studies have reported comparable results regarding this association between type 2 diabetes and periodontal disease ${ }^{20}$.

We find that current smokers comprise $28.8 \%$ of our total study participants, and these smokers present a slightly higher prevalence of gingival inflammation than nonsmokers in our study, but this finding was not statistically significant. These results contrast with the findings of Müller, et al. ${ }^{25}$ (2002), in which study participants (soldiers of the German Armed Forces serving between December 1999 and May 2000) who smoked were found to have more prevalent bleeding on probing and more calculus than nonsmokers. Smoking was first identified as a risk factor in periodontal diseases from an analysis of data by I smail, et al. ${ }^{18}$ from data collected from 1971 to 1975. An analysis by the National Health and Nutrition Examination Survey in the U.S. (NHANES I) was able to demonstrate an association between smoking and periodontal diseases that was independent of oral hygiene, age, or other probable risk factors. Since then, there has been enough evidence to identify smoking as a risk factor for periodontitis ${ }^{13}$. Studies performed in randomly chosen groups of patients demonstrated that tobacco use and oral hygiene are risk indicators for periodontitis; in particular, smokers were invariably shown to have a higher prevalence and 
progression of destructive periodontal diseases ${ }^{24}$.

There is a strong need in Latin America to focus on more effective intervention programs to prevent and control periodontal diseases at national levels. It should be emphasized that since periodontitis begins as gingivitis, it is reasonable to conclude that the control of gingival inflammation can be beneficial to the population as a whole to prevent both the onset and the progression of periodontal damage caused by periodontitis. While the disability-adjusted life-years (DALYs) due to severe periodontitis and untreated caries have increased since 1990, those due to severe tooth loss have decreased. Oral conditions are all ranked among the top 100 detailed causes of DALYs ${ }^{23}$. These findings highlight the challenge in responding to the diversity of urgent oral health needs worldwide, particularly in developing communities.

Gingival inflammation, which could be considered a reversible and easily controlled disease in stage of gingivitis, is found to be highly prevalent among adult study participants from the three cities in Latin America of this study. In addition, these individuals are also more likely to attend preventive or followup visits because socioeconomic characteristics (such as income and level of education) influence the pattern and type of dental services used ${ }^{6}$. Poor awareness of the importance of periodontal health and the consequences of the disease among the public and even among some general dental practitioners is one of the most common reasons for failure to control and treat periodontal diseases effectively on a population basis ${ }^{19}$. We recommend that effective intervention programs for the prevention and control of periodontal diseases should be implemented at national levels, and the need for such implementation seems to be extremely important in the three countries we studied here. We believe that there is a strong need across Latin America to improve the population's self-awareness about oral health through better oral health education that promotes good oral hygiene and regular dental care.

This study was aimed to detect gingival inflammation instead of establishing the diagnosis of either gingivitis or periodontitis in order to determine the risk of gingivitis onset or periodontitis progression in the study population.

\section{CONCLUSI ONS}

Considering our findings together, it is possible to conclude that gingival inflammation is highly prevalent in the three Latin American cities studied. Overall, $95.6 \%$ of the participants aging 18 years or older had gingival inflammation, considering that more than two-thirds have moderate gingival inflammation and $3.6 \%$ have severe gingival inflammation. In general terms, the presence of gingival inflammation is positively associated with risk indicators such as gender, socioeconomic variables, and the presence of plaque. The present investigation serves as the basis for a longitudinal analysis of oral health in populations of South American adults, and for the development of strategies to improve the health care systems that serve them.

\section{ACKNOWLEDGEMENTS}

The present study was kindly supported by an independent research grant from Colgate Palmolive, Piscataway, New J ersey, № CRO- 2013-03-GI N-SC$B S$. The authors declare that there is no conflict of interest for any authors related to the content of the present analysis.

\section{REFERENCES}

1- Ababneh KT, Abu Hwaij ZM, Khader YS. Prevalence and risk indicators of gingivitis and periodontitis in a multi-centre study in North Jordan: a cross sectional study. BMC Oral Health. 2012; 12: 1. 2- Albandar J M. Periodontal diseases in North America. Periodontol 2000. 2002; 29: 31-69.

3- Albandar J M, Brunelle JA, Kingman A. Destructive periodontal disease in adults 30 years of age and older in the United States, 1988-1994. J Periodontol. 1999;70(1):13-29.

4- Australian Research Centre for Population Oral Health, The University of Adelaide, South Australia. Periodontal diseases in the Australian adult population. Aust Dent J. 2009;54(4):390-3. 5- Baehni PC, Takeuchi Y. Anti-plaque agents in the prevention of biofilm-associated oral diseases. Oral Dis. 2003;9 Suppl 1:23-9. 6- Barbato PR, Muller Nagano HC, Zanchet FN, Boing AF, Peres MA. Tooth loss and associated socioeconomic, demographic, and dental-care factors in Brazilian adults: an analysis of the Brazilian Oral Health Survey, 2002-2003. Cad Saude Publica. 2007;23(8): 1803-14.

7- Burt B, Research, Science and Therapy Committee of the American Academy of Periodontology. Position paper: epidemiology of periodontal diseases. J Periodontol. 2005; 76(8): 1406-19.

8- Craig RG. Destructive periodontal diseases, systemic inflammation, and atherosclerotic complications: the emerging role of the dental profession. J Calif Dent Assoc. 2009;37(11):773-7. 9- Crocombe LA, Brennan DS, Slade GD, Loc DO. Is self interdental cleaning associated with dental plaque levels, dental calculus, gingivitis and periodontal disease? J Periodontal Res. 2012; 47(2): 188-97.

10- Do LG, Slade GD, Roberts-Thomson KF, Sanders AE. Smokingattributable periodontal disease in the Australian adult population. J Clin Periodontol. 2008; 35(5):398-404.

11- Farina R, Scapoli C, Carrieri A, Guarnelli ME, Trombelli L. Prevalence of bleeding on probing: a cohort study in a specialist periodontal clinic. Quintessence Int. 2011;42(1):57-68.

12- Gamonal J, Mendoza C, Espinoza I, Muñoz A, Urzúa I, Aranda W, et al. Clinical attachment loss in Chilean adult population: First Chilean National Dental Examination Survey. J Periodontol. 2010; 81(10): 1403-10.

13- Genco RJ, Borgnakke WS. Risk factors for periodontal disease. Periodontol 2000. 2013;62(1):59-94.

14- Haas AN, Wagner MC, Oppermann RV, Rösing CK, Albandar JM, Susin C. Risk factors for the progression of periodontal attachment loss: a 5-year population-based study in South Brazil. J Clin Periodontol. 2014;41(3):215-23. 
15- Hermann P, Gera I, Borbély J, Fejérdy P, Madléna M. Periodontal health of an adult population in Hungary: findings of a national survey. J Clin Periodontol. 2009; 36(6):449-57.

16- Hugoson A, Norderyd O. Has the prevalence of periodontitis changed during the last 30 years? J Clin Periodontol. 2008; 35(8 Suppl): 338-45.

17- Hugoson A, Sjödin B, Norderyd O. Trends over 30 years, 19732003 , in the prevalence and severity of periodontal disease. J Clin Periodontol. 2008; 35(5): 405-14.

18- Ismail Al, Burt BA, Eklund SA. Epidemiologic patterns of smoking and periodontal disease in the United States. J Am Dent Assoc. 1983; 106(5):617-21.

19- J in LJ , Armitage GC, Klinge B, Lang NP, Tonetti M, Williams RC. Global oral health inequalities: task group - periodontal disease. Adv Dent Res. 2011;23(2):221-6.

20- Kaur G, Holtfreter B, Rathmann W, Schwahn C, Wallaschofski $\mathrm{H}$, Schipf $\mathrm{S}$, et al. Association between type 1 and type 2 diabetes with periodontal disease and tooth loss. J Clin Periodontol. 2009; 36(9): 765-74.

21- Li Y, Lee S, Hujoel P, Su M, Zhang W, Kim J, et al. Prevalence and severity of gingivitis in American adults. Am J Dent. 2010;23(1): 9-13.

22- Mamai-Homata E, Polychronopoulou A, Topitsoglou V, Oulis C, Athanassouli T. Periodontal diseases in Greek adults between 1985 and 2005 - risk indicators. Int Dent J. 2010;60(4):293-9.
23- Marcenes W, Kassebaum NJ, Bernabé E, Flaxman A, Naghavi M, Lopez A, et al. Global burden of oral conditions in 1990-2010: a systematic analysis. J Dent Res. 2013;92(7):592-7.

24- Mdala I, Olsen I, Haffajee AD, Socransky SS, Thoresen M, de Blasio BF. Comparing clinical attachment level and pocket depth for predicting periodontal disease progression in healthy sites of patients with chronic periodontitis using multi-state Markov models. J Clin Periodontol. 2014;41(9):837-45.

25- Müller HP, Stadermann S, Heinecke A. Longitudinal association between plaque and gingival bleeding in smokers and nonsmokers. J Clin Periodontol. 2002;29(4):287-94.

26- Offenbacher S, Barros SP, Paquette DW, Winston J L, Biesbrock $A R$, Thomason RG, et al. Gingival transcriptome patterns during induction and resolution of experimental gingivitis in humans. J Periodontol. 2009; 80(12): 1963-82.

27- Oppermann RV, Haas AN, Rösing CK, Susin C. Epidemiology of periodontal diseases in adults from Latin America. Periodontol 2000. 2015;67(1): 13-33.

28- Shimada Y, Tabeta K, Sugita N, Yoshie H. Profiling biomarkers in gingival crevicular fluid using multiplex bead immunoassay. Arch Oral Biol. 2013; 58(6): 724-30.

29- Stamm JW. Epidemiology of gingivitis. J Clin Periodontol. $1986 ; 13(5): 360-6$.

30- Zhang J, Xuan D, Fan W, Zhang X, Dibart S, De Vizio W, et al. Severity and prevalence of plaque-induced gingivitis in the Chinese population. Compend Contin Educ Dent. 2010;31(8):624-9. 